\title{
Radiation Retinopathy: Detection and Management Strategies
}

\author{
Niroj Kumar Sahoo (D) \\ Richa Ranjan (D) ${ }^{2}$ \\ Mudit Tyagi $\mathbb{1}^{3}$ \\ Hitesh Agrawal ${ }^{3}$ \\ Subhakar Reddy ${ }^{3}$ \\ 'Department of Retina and Vitreous, \\ L V Prasad Eye Institute, Vijayawada, \\ India; ${ }^{2}$ Bharti Eye Foundation and \\ Hospital, New Delhi, India; ${ }^{3} \mathrm{Smt}$. Kanuri \\ Santhamma Centre for Vitreo-Retina \\ Diseases, L V Prasad Eye Institute, \\ Hyderabad, India
}

\begin{abstract}
A gradual shift in trend from primary enucleation to globe salvaging radiation therapy for the management of ocular tumors has resulted in the rise of several posttreatment ocular complications including radiation retinopathy. Radiation retinopathy is a chronic, progressive, and occlusive vasculopathy that can manifest anytime between 1 month to 15 years after starting radiation therapy. The aim of treatment in most of these cases is to prevent further vision loss. Treatment options such as laser photocoagulation, antivascular endothelial growth factor and intraviral steroids have been described. However, despite several advances in diagnostic and therapeutic modalities, a significant proportion of eyes with radiation retinopathy eventually go blind. This review summarises some of the clinical features, investigative modalities, and recent therapeutic strategies used in the management of radiation retinopathy.
\end{abstract}

Keywords: radiation retinopathy, radiation maculopathy, anti-VEGFs, laser photocoagulation, ocular tumors

\section{Introduction}

Radiation therapy is an invaluable tool in the management of ocular tumors. It has been a popular alternative to enucleation for patients with choroidal melanoma, retinoblastoma, and ocular metastases, ${ }^{1-3}$ and has proven to be a life-saving treatment for several orbital, peri-orbital, and intracranial tumors. Since its inception, radiotherapy has evolved significantly, both in terms of efficacy and safety. The popularity of radiation therapy in ocular tumors also stems from the Collaborative Ocular Melanoma Study (COMS), which showed similar survival rates to radiotherapy when compared to enucleation. The results of COMS led to a shift towards globe-salvaging therapeutic strategies. ${ }^{5}$ Despite advances in precise localization and dosage calculation, patients encounter several forms of ocular complications as collateral damage. Radiation retinopathy (RR) is a chronic progressive vasculopathy developing secondary to ionizing radiation to the retina. Stallard, in 1933, was the first to describe the hazardous effects of ionizing radiation on retina, in patients with retinoblastoma 3-6 weeks after treatment with radon seeds. ${ }^{6}$ The author described the occurrence of retinal hemorrhages, vascular sheathing, disc edema, and exudation following irradiation. Since then, there have been several reports of RR following brachytherapy, external beam radiotherapy, proton beam radiation, helium ion radiotherapy, and gamma knife radiotherapy for various intraocular or orbital cancers. ${ }^{1,7-10}$

Various retrospective and prospective studies have explored several treatment options; however, there is no standard treatment for RR. This article comprises
Correspondence: Mudit Tyagi Smt. Kanuri Santhamma Centre for Vitreo-Retinal Diseases, L V Prasad Eye Institute, Banjara Hills, Hyderabad, 34, India

Tel +9l-9553339042

Email drmudittyagi@gmail.com 
a review of clinical features and investigations of radiation retinopathy and the current strategies being studied for its treatment.

\section{Epidemiology and Risk Factors}

While radiotherapy offers an eye-sparing alternative for patients and allows them to maintain some level of visual acuity, an increase in the incidence of radiation-related complications has been seen. ${ }^{11,12}$ COMS reported that after 3 years of treatment, nearly $50 \%$ of patients had a visual acuity of 20/200 or worse. ${ }^{13}$ Several factors determine the incidence of radiation retinopathy. The risk factors can be divided into intrinsic or extrinsic. One of the most important intrinsic/patient factors is the presence of concurrent diabetes. There appears to be a synergistic action of radiation and diabetes on the capillaries that predisposes these eyes to retinopathy and can increase the risk of visual loss by $300 \% .{ }^{14,15}$ The cumulative effect of pericytes damage seen in diabetes and endothelial damage seen with radiation exposure culminates in the severe occlusive arteritis, which is commonly seen in cases of radiation retinopathy. Diabetes has also been associated with poor visual outcomes due to a higher incidence of developing neovascular glaucoma ${ }^{16}$ and diabetic papillopathy. ${ }^{17}$ The risk of disease is also increased for patients with other vasculopathies like hypertension and coronary artery disease. ${ }^{14,15,18}$ Tumor characteristics and patient demographics play a crucial role in the development of RR. ${ }^{14,15,18}$ Eyes with larger tumors may require high doses of radiation, increasing the chance of developing RR. ${ }^{19}$ Also, eyes with tumor proximity to the critical structures of the eye such as the optic disc or macula are at high risk for developing vision loss in the form of radiation optic neuropathy or radiation maculopathy (RM). ${ }^{20}$ Concomitant chemotherapy makes the retinal vasculature more vulnerable to radiation damage by increasing oxygen-derived free radicals. ${ }^{21}$ It also increases the risk of progression to the proliferative stage, ${ }^{22}$ higher visual morbidity, ${ }^{21,23}$ development of retinopathy at lower radiation dose, ${ }^{23}$ and decrease in the latent period between exposure and retinopathy. ${ }^{23,24}$ Krema et al also reported clinical risk factors for the development of RR, and found pre-existing diabetes, prior or concurrent chemotherapy, larger irradiated retinal area, and posterior location of the irradiated area in the ocular fundus, to have a higher association. ${ }^{25}$ Pregnancy has been thought to accelerate radiation retinopathy. ${ }^{26}$
Extrinsic factors responsible for the development of $R R$ are related to the radiation itself. These include the type of radiation, radiation dose, fractionation schedule, elapsed time in the course of treatment, and errors in treatment. ${ }^{20,21,27-31}$ Parsons et al reported a 53\% rate of $\mathrm{RR}$ in patients who received 45 to $55 \mathrm{~Gy}$ doses to half or more of the retina during external beam radiation for extracranial tumors. ${ }^{27}$ Most small to medium-sized tumors ( $\leq 10 \mathrm{~mm}$ in height or $\leq 16 \mathrm{~mm}$ in largest base diameter) are treated with radiation therapy, whereas most large tumors ( $>10 \mathrm{~mm}$ in height or $>16 \mathrm{~mm}$ in largest base diameter) are treated solely by enucleation. ${ }^{32}$ Shields et al found that tumor base $\geq 10 \mathrm{~mm}$, tumor thickness $>8 \mathrm{~mm}$, the radiation dose to the tumor base of $\geq 33,300 \mathrm{cGy}$, and increasing radiation dose to the optic disk to be significant predictors of long-term poor visual acuity. ${ }^{33}$ However, Horgan et al found no such association. ${ }^{34}$ The authors found pretreatment tumor size to be the single most significant predictor for maculopathy in multivariate analysis. Gunduz et al reported in their study that $42 \%$ of patients develop non-proliferative RR within 5 years of treatment for posterior uveal melanoma. ${ }^{12}$ Krema et al further reported that $30 \%$ of patients treated with plaque brachytherapy for melanoma developed evidence of $R R$ within 2 years of treatment. ${ }^{8}$ Ruthenium-106 has been shown to have limited depth of penetration, resulting in less radiation exposure to surrounding retinal structures. ${ }^{35,36}$ However, when compared to Iodine-125, rates RR have been seen to be similar between the two, ${ }^{37}$ although a few studies have reported slightly higher rates for Iodine-125. ${ }^{35,36}$ Considering the slight advantage of Iodine-125 in certain cases in terms of tumor control, ${ }^{37,38}$ the choice of plaque can be individualised on a case-tocase basis. The risk of RR following proton beam irradiation has been reported to be higher, with rates ranging between $85 \%$ and $90 \% .{ }^{39-41}$ Inclusion of more posteriorly located tumors in these studies could have resulted in the higher incidence seen. Hyper-fractionation with a dose of less than $1.9 \mathrm{G} /$ fraction has been demonstrated to decrease the risk of RR development. ${ }^{27,31}$ Although the worst visual outcome has been seen after gamma knife treatment (reported to cause complete vision loss in as many as $50 \%$ of the eyes), ${ }^{10}$ it needs to be emphasized here that gamma knife treatment still remains a valid treatment option in selected cases, with excellent results. ${ }^{42}$ The area of retina irradiated also plays a significant role in RR manifestations. Takeda et al showed that eyes receiving more than 50 Gy to greater than $60 \%$ of the retina have 
a higher risk of developing RR. ${ }^{20} \mathrm{RR}$ usually develops after around 6 months to 3 years (range 1 month to 15 years) following radiation therapy. In one study, the mean time to development of proliferative RR was found to be 32 months and was found in $7 \%$ of patients at 10 to 15 years after treatment. ${ }^{43}$ The type of radiation therefore plays an important role in this latency period, with higher dose and single fraction regimen resulting in lower latency period. ${ }^{44}$ Thus, we recommend close monitoring, with 6 monthly follow-ups if there are no signs of retinopathy, and subsequent follow-ups can be tailored on a case-tocase basis. Detection and follow-up of RR can be especially challenging when the patients are being treated with external beam radiotherapy (EBRT) and are less likely to be seen by an ophthalmologist.

\section{Pathogenesis}

Following radiotherapy, the primary retinal vascular event is an endothelial cell loss followed by vascular occlusion and capillary dropout, which results in vascular incompetence and retinal ischemia. ${ }^{45}$ Radiation significantly alters the structure and function of the retinal microvasculature due to the compromised blood-retinal barrier. ${ }^{46}$

It is hypothesized that exposure to radiation causes preferential loss of vascular endothelial cells with a relative sparing of the pericytes. ${ }^{45}$ Ionizing radiation can cause direct damage to molecular bonds, resulting in damage to DNA base-pairs, cell membranes rupture and lysosome disruption. ${ }^{47}$ This affects the cell's ability to divide, and they undergo senescence and eventually die. Radiation can also cause indirect damage to cells by exposing the endothelial cells to high concentrations of free radicals that result in cell membrane damage. ${ }^{47,48}$ This leads to occlusion of capillary beds and subsequent microaneurysm formation. The areas of retinal non-perfusion cause retinal ischemia, which eventually leads to macular edema, neovascularization, vitreous hemorrhage, and tractional retinal detachment. This could be one of the reasons why signs of retinopathy predominate in the macular region, where oxygen concentration is highest. Nonreplicating cells like photoreceptors are relatively resistant to radiation damage. Patchy degeneration of the RPE in the form of loss of melanin, accumulation of lipofuscin, and hyperplasia, and beading, telangiectasia, microaneurysm, sclerosis and closure of choroidal vessels, have also been described. ${ }^{47,49,50}$

\section{Clinical Features}

RR can closely resemble diabetic retinopathy, as the manifestations and patterns of progression of these two entities are very similar. Both diseases progress from a nonproliferative to a proliferative stage and can result in rapid deterioration of vision. Clinical manifestations of RR include microaneurysms, macular edema, cottonwool spots, hard exudates, retinal edema, telangiectasia, and perivascular sheathing, which may follow in variable sequence and latency (Figures 1 and 2). ${ }^{51,52}$ Microaneurysms are the first ophthalmoscopically detectable structural changes to appear in RR and are almost universally present. $^{51}$ The clinical manifestations of RR are more often severe in the posterior than in the anterior retina, which is due to higher blood flow of the macula. ${ }^{52}$ Ischemic retinal changes include macular capillary nonperfusion, nerve fiber layer infarcts, retinal neovascularisation, choriocapillaris non-perfusion, choroidal ischemia, vitreous hemorrhage, tractional retinal detachment, exudative retinal detachment, and neovascular glaucoma (Figure 3). ${ }^{52}$ Ghost vessels can appear in the later part of the disease. The retina is the most common site of neovascularization. The percentage of eyes with neovascularization elsewhere (NVE) only is around 43\%, which is similar to those seen in diabetic retinopathy, while the percentages for neovascularization of disc (NVD) only and NVD with NVE are less than that seen in proliferative diabetic retinopathy (PDR). ${ }^{22}$ Rarely, choroidal neovascularization, ${ }^{53}$ retinal angiomatous proliferation, ${ }^{54}$ intravitreal polypoidal choroidal vasculopathy, ${ }^{55}$ can occur after radiotherapy. Also, RR can also often coexist with other ocular complications of radiotherapy like radiation keratopathy, cataract, and radiation optic neuropathy. ${ }^{56}$ It is particularly important to distinguish RR from another post-radiotherapy complication, known as "toxic tumor syndrome", which is characterized by exudative retinal detachment and iris rubeosis. While RR develops as a result of direct damage of the healthy retina by the ionizing radiation, toxic tumor syndrome has been hypothesized to result from radiation-induced vasculopathy within the tumor, which causes exudation from the damaged and incompetent tumor vasculature. ${ }^{57}$

Several factors influence the progression of the disease from the non-proliferative to the proliferative stage of the disease. Kinyoun et al showed an increased risk of developing proliferative retinopathy in eyes with shorter latency (less than 24 months) between the administration of 


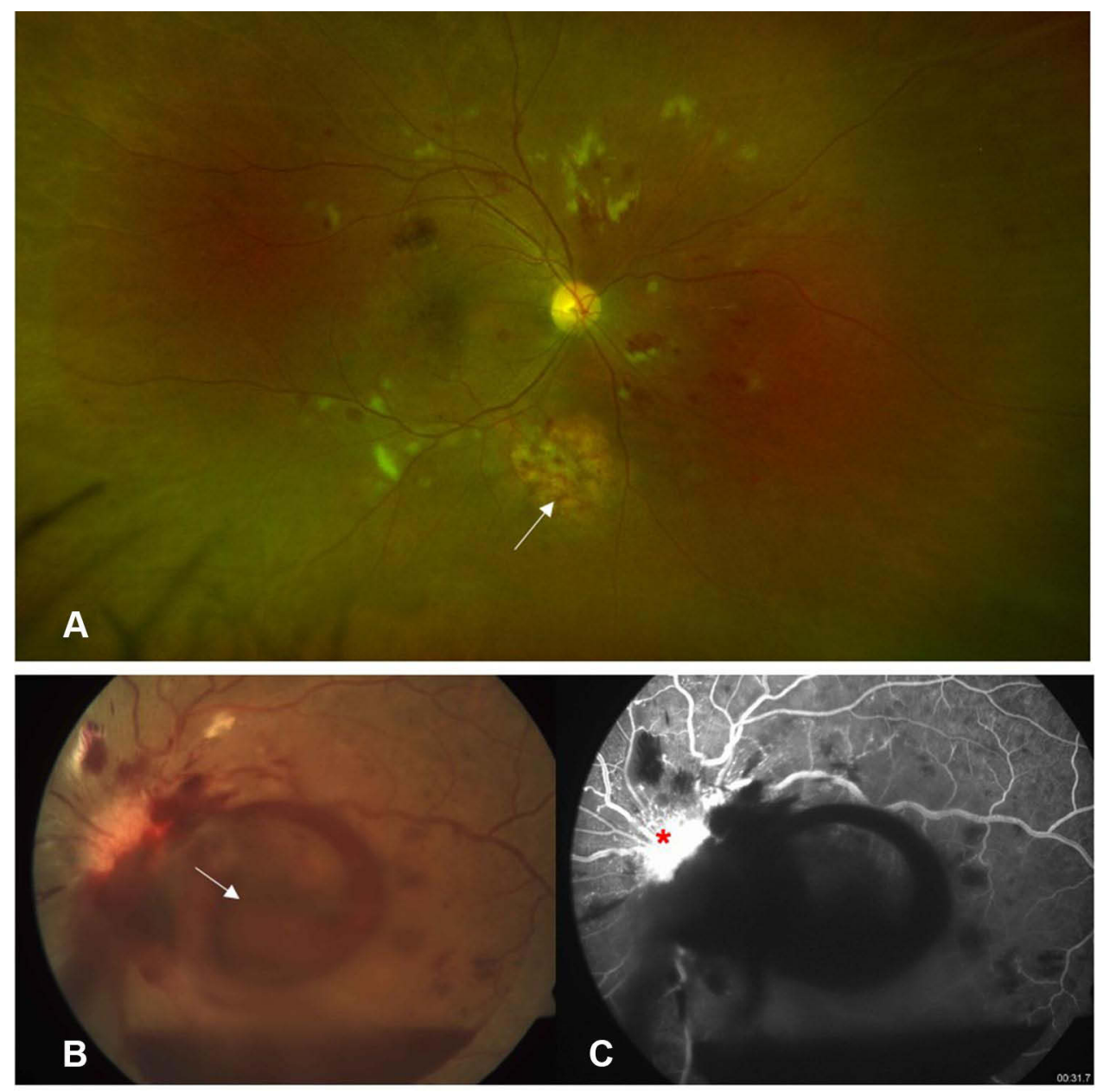

Figure I (A) Non-proliferative stage of radiation retinopathy following external beam radiation therapy for adenocarcinoma of lung with brain metastasis. White arrow points towards area of choroidal metastasis. Fundus photo (B) of a patient with proliferative stage of radiation retinopathy after radiotherapy for cerebellar metastasis, showing preretinal hemorrhage (white arrow) over macula, while fundus fluorescein angiography (C) confirmed the presence of a leaking neovascularization of disc (red asterisk).

treatment and appearance of retinopathy than those with a higher period. On the other hand, eyes that have been followed up for 4 years or more have been seen to have a lesser risk of converting to proliferative retinopathy. The authors also suggested that a decreased initial visual acuity (less than 20/40) was associated with conversion to the proliferative stage. These baseline factors described indicate a more severe ischemic status of the retina with greater stimulus for new vessel formation. Eyes with proliferative retinopathy invariably progress to legal blindness without treatment and even those in the non-proliferative stage tend to gradually lose vision over time. ${ }^{22}$

\section{Differential Diagnosis}

Clinical features of RR can be difficult to distinguish from other vascular diseases of the retina like diabetic retinopathy, hypertensive retinopathy, and other vascular occlusive disorders. Thus, a dilated ophthalmic examination, a careful documentation of history, along with a thorough review of the treatment records, is usually necessary to reach a diagnosis.

RR should be considered as a differential diagnosis after cephalic radiation for head and neck malignancies. Diabetic retinopathy and RR are closely associated and sometimes both may coexist. RPE atrophy and, possibly, unilaterality of the disease are the two features of RR that can distinguish it from diabetic retinopathy. There are also fewer microaneurysms in cases of RR as compared to diabetic retinopathy. ${ }^{58}$ Other conditions that can closely mimic radiation retinopathy are retinal vein occlusions, ocular ischemic syndrome, hypertensive retinopathy, Coats' disease, and parafoveal telangiectasia [12].

Apart from meticulous clinical examination and adequate history taking, newer multimodal imaging such as 

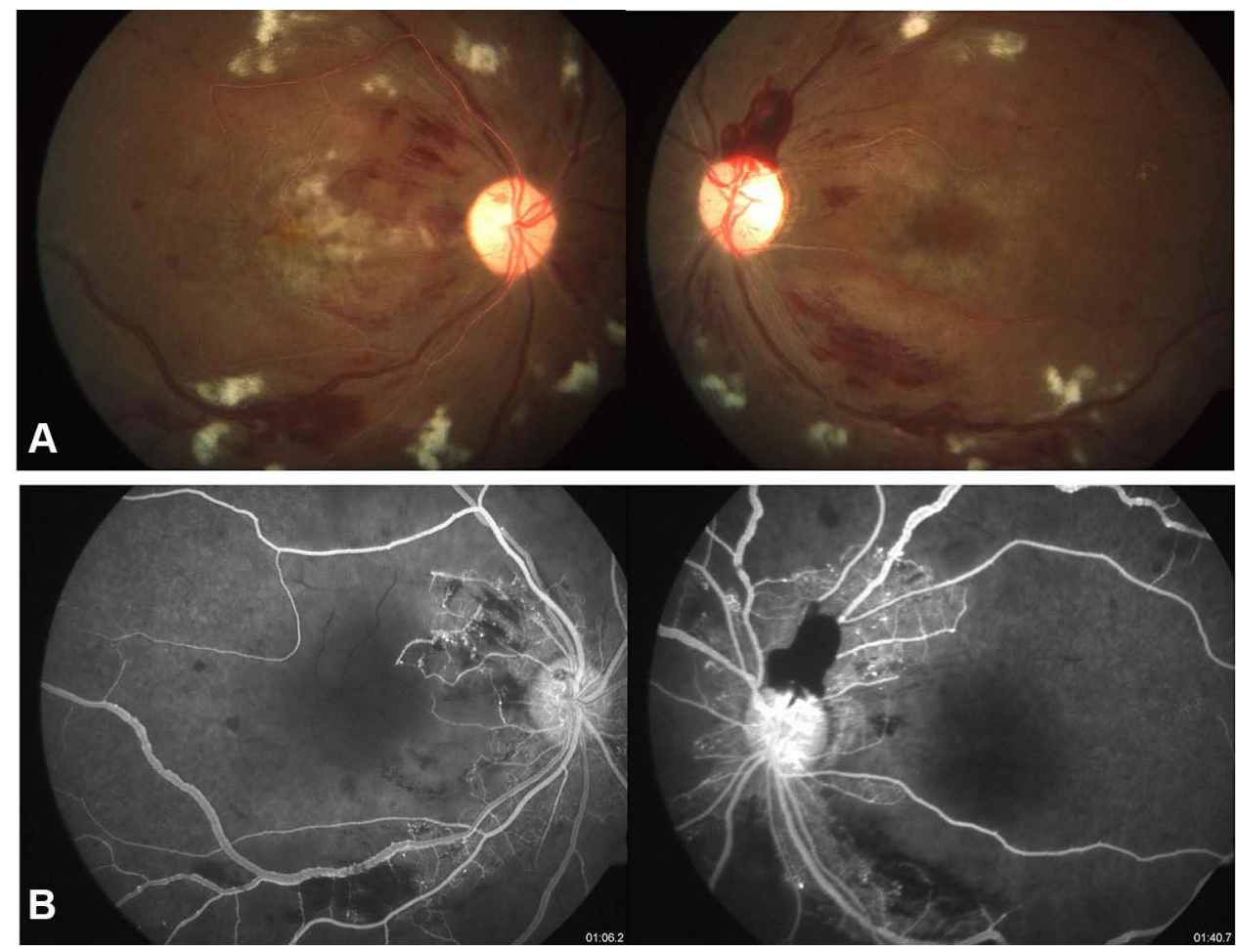

Figure 2 Clinical picture (A) fundus fluorescein angiography $(\mathbf{B})$ demonstrating severe macular ischemia in a case of radiation retinopathy.

optical coherence tomography (OCT), OCT angiography (OCTA), fundus fluorescein angiography (FFA), and indocyanine green angiography (ICGA) are useful in making diagnosis and treatment of RR.

\section{Investigation}

Clinical features of radiation retinopathy can often be unremarkable in the early stages of the disease, and it might be necessary to take the help of adjunctive investigations.

\section{Optical Coherence Tomography (OCT)}

One of the earliest manifestations of radiation retinopathy is macular edema and has been seen in as many as $33 \%$ of eyes with no clinically apparent retinopathy. ${ }^{34,41,59}$ Thus, OCT can be one of the most sensitive modalities for the detection of early retinopathy. Macular edema on OCT can manifest almost 5 months earlier than clinically detectable retinopathy, and it has been found as early as 4 months following plaque radiotherapy (peak incidence at 12 months with a plateau between 18 and 24 months). ${ }^{34}$

Depending upon the severity of the retinopathy, radiation maculopathy may manifest as cystoid or non-cystoid edema that involves the foveal or extra-foveal macula. A neuro-sensory detachment may or may not be present.
Other features include the presence of hyper-reflectivity in the inner retinal layers (suggestive of ischemia), hyperreflective dots corresponding to the intraretinal exudates, disorganization of retinal inner layers, or outer retinal disruption in late stages. Based on the severity of macular edema, Horgan et al described a five-point classification scale: $^{34}$

1. Grade 1: Extra-foveolar non-cystoid edema.

2. Grade 2: Extra-foveolar cystoid edema.

3. Grade 3: Foveolar non-cystoid edema.

4. Grade 4: Foveolar cystoid edema-mild to moderate.

5. Grade 5: Foveolar cystoid edema-severe.

Increasing severity of macular edema was also shown to correlate with the foveal thickness and a decreasing visual acuity.

\section{Fundus Fluorescein Angiography}

The primary lesion responsible for the manifestations of radiation retinopathy is vascular endothelial damage and thus can lead to variable degrees of vascular occlusion. The vascular obliteration can range from retinal capillary obliteration, retinal arterial branch occlusion, or central retinal artery occlusion. ${ }^{60}$ Retinal veins, although less 

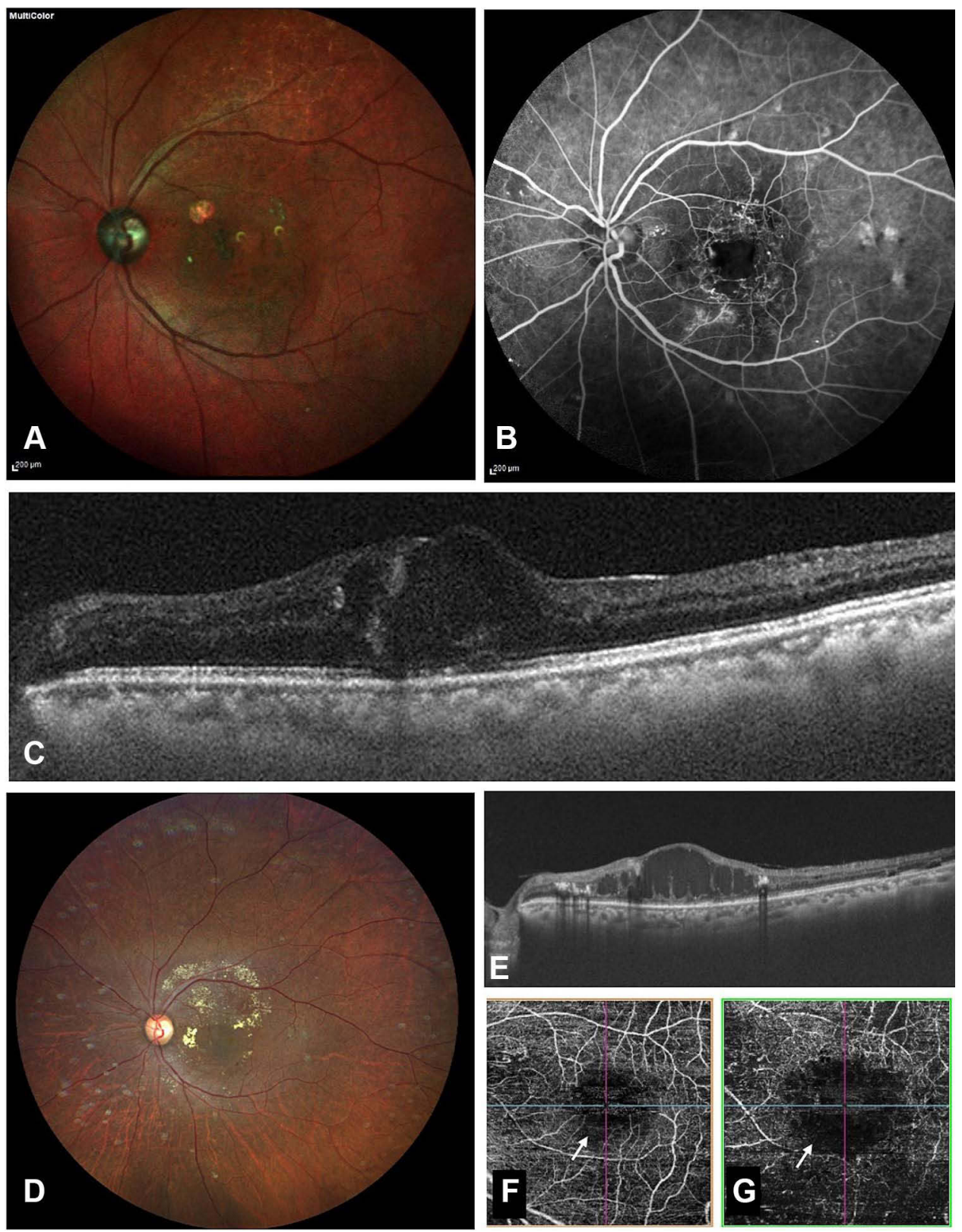

Figure 3 A 49-year old male presented with decreased vision in his left eye 3 years after treatment with external beam radiotherapy for orbital lymphoma. His visual acuity at presentation was 20/100. Fundus examination (A) showed few hemorrhages over macula with clinically evident macular edema . Fundus fluorescein angiography (B) demonstrated multiple microaneurysms and leaking capillaries with enlarged, irregular foveal avascular zone (FAZ) . Optical coherence tomography (OCT) showed center involving macular edema (C). The patient received multiple anti-VEGF injections. At the end of 12 months follow-up, vision was maintained at $20 / 125$. Fundus examination at 12 months visit showed a few hard exudates and few hemorrhages over macula (D). OCT (E) at this visit showed a chronic refractory macular edema and an increase in FAZ size could be seen demonstrated on OCT angiography in both superficial (F) and deep capillary (G) slab.

susceptible to damage, have also been reported. ${ }^{61}$ Capillary non-perfusion areas are one of the most consistent findings in RR and appear before larger vessels are affected. $^{23}$ The authors suggested that the finding is so common that the diagnosis of radiation retinopathy is difficult to entertain without it. Other changes visible on angiography include microaneurysms, hypo-fluorescence from retinal hemorrhages, nerve fiber layer infarcts, and leakage due to perivascular sheathing, intraretinal exudation, and retinal or optic disk neovascularization.

Amoaku et al used fluorescein angiography to classify changes in radiation retinopathy based on microvascular changes into four stages: ${ }^{62}$

- Grade 1: Small foci of dilated and irregular retinal capillaries along with isolated or small clusters of 
microaneurysms. Subtle evidence of capillary closure, without detectable microvascular incompetence or fluid accumulation, can be seen. Vision is usually very good.

- Grade 2: Multiple foci of dilated and telangiectatic capillaries and zones of capillary closure up to one optic disc area. Usually, numerous microaneurysms and focal leakage of dye from defective capillaries in later phase angiograms can be seen. It may be associated with clinically observable retinal edema. Visual acuity is relatively good.

- Grade 3: Characterised by widespread capillary dilatation, telangiectatic-like channels, microvascular incompetence, and significant areas of capillary closure (1-4 disc areas). These eyes can have significant macular edema with or without cystoid macular degenerative changes. Microaneurysms and intra-retinal microvascular abnormalities commonly occur at the border of perfused and nonperfused retina. These eyes usually have poor visual acuity.

- Grade 4: Characterised by widespread disorganization of the retinal microvasculature with extensive inner retinal ischemia, non-perfused retina more than four disc-areas, pre-retinal neovascularisation, rubeosis iridis and vitreous hemorrhage. Visual acuity is usually very poor.

Based on FFA, macular edema can also be classified into diffuse, focal, and mixed patterns based on the pattern of dye leakage. Over time, an increase in the number of microaneurysms and area of non-perfused retina, despite considerable microaneurysm turnover and attempts at revascularisation of ischaemic areas, can be seen. ${ }^{62}$ Although the changes seen in RR are irreversible, attempts to recanalize nonperfused capillary beds have occasionally been observed. ${ }^{62}$

Post-treatment angiography usually shows some deformed and collapsed telangiectatic vessels that fail to perfuse with dye, adjacent to photocoagulation burns. Micro aneurysms either decrease in size, disappear or become less permeable to dye after treatment. ${ }^{62}$

On the basis of clinical and angiographic findings, Finger and Kurli proposed another classification in $2005 .^{63}$

Stage 1 extramacular ischemic changes,

Stage 2 macular ischemic changes, and
Stage 3 included additional macular edema and extramacular retinal neovascularization.

Stage 4 encompassed vitreous hemorrhage and at least 5 disc areas of retinal ischemia.

The study showed that macular edema appears early in the disease, and in the absence of ischemia, has a good prognosis. However, the classification combined the macular and extramacular changes and thus did not gain much popularity.

\section{OCT Angiography}

Being a disease primarily of retinal microvasculature, OCTA is extremely sensitive in detecting early disease. Apart from being a non-invasive test, OCTA delineates most of the changes seen on FFA better, and scores above FFA in many other aspects. The high definition and the ability to segment individual layers of the retina allow quantification at the capillary level. Shields et al demonstrated enlargement of FAZ and decreased parafoveal capillary density in both superficial and deep capillary plexuses, even in eyes without clinically evident macular edema. ${ }^{64,65}$ These OCTA features have also been shown to have a significant impact on visual acuity. ${ }^{40}$ Skalet et al found a reduced peripapillary capillary density compared to the fellow eye, which correlated inversely with the radiation dose to the optic nerve and visual acuity. ${ }^{66}$ These changes appear before the appearance of clinically apparent retinopathy and have been seen to progress with the progression of retinopathy.

\section{Treatment}

Although spontaneous improvement can occur, it is very uncommon. ${ }^{67}$ There are no specific guidelines for treatment and the primary goal in most cases remains visual stabilization or prevention of vision loss. Due to similarities in pathogenesis and natural history, treatment of radiation retinopathy follows closely to that of diabetic retinopathy. The type of retinopathy determines the management protocol

\section{Laser Photocoagulation}

Chaudhuri et al described therapeutic success with the use of argon laser photocoagulation for proliferative retinopathy and vitreous hemorrhage and reported angiographic evidence regression of neovascularisation 2 weeks posttreatment. ${ }^{68}$ Kinyoun et al published similar results and also suggested that fewer spots should be used during 
treatment in order to reduce the degree of field loss and consecutive optic atrophy that may be added to radiationrelated optic atrophy. ${ }^{49}$ In spite of the regression of neovascularisation, these eyes usually keep having deterioration in vision due to several factors such as radiation optic neuropathy, macular ischemia, macular edema, radiation cataract, vitreous hemorrhage, tractional retinal detachment, and neovascular glaucoma. Vitreous hemorrhage often requires vitrectomy with endolaser or cryotherapy. Finger and Kurli also reported the use of laser photocoagulation to ablate the ischemic zone after radiotherapy. ${ }^{63}$ Their findings suggested that laser photocoagulation of the irradiated extramacular zones was effective in preventing or regressing radiation retinopathy. ${ }^{63}$

Before the era of anti-VEGF, most of the published literature recommended focal or grid lasers for the treatment of macular edema. Several studies have demonstrated its efficacy in the reduction of macular thickness. Kinyoun et al used argon laser to ablate microaneurysms/ leaking vessels and capillary non-perfusion areas and demonstrated a reduction in macular thickness and prevention of vision loss. ${ }^{49}$ Similar results were obtained by Amaoku and Archer who showed visual improvement within 2-3 months of macular laser that was maintained at one-year post-treatment. ${ }^{69}$ Despite the early encouraging results, it was soon realized that the visual improvement post-laser was ill-maintained. Hykin et al showed that although there was a statistically significant improvement in visual acuity at 6 months post laser with reduced risk of vision loss at 12 months, little benefit was seen by 2 years, with almost $16 \%$ of treated eyes developing halving of visual angle. ${ }^{70}$

\section{Anti-VEGF Agents}

Like diabetic retinopathy, VEGF has been considered as the primary pathogenic stimulus in radiation retinopathy. Thus, the introduction of anti-VEGF agents has opened many doors to the treatment of radiation maculopathy. Bevacizumab is a full-length humanized monoclonal antibody that binds to all types of VEGF, which acts by inhibiting the formation of abnormal blood vessels, thereby decreasing vascular permeability. By the time its use started in radiation retinopathy, it had already established its efficacy in the treatment of several retinal diseases like diabetic retinopathy, retinal vein occlusion, and age-related macular degeneration. Initial reports on the use of Bevacizumab provided encouraging results in a small subset of eyes. ${ }^{71,72}$ The variable response to anti-VEGF agents was attributed to a combination of multiple factors including long-standing macular edema or when direct irradiation was received by the fovea.

Therapeutic agents like ranibizumab and aflibercept have been FDA approved for a multitude of retinal diseases. However, there has been no approved anti-VEGF for use in radiation maculopathy to date. Finger et al showed that ranibizumab is safe, tolerable with as many as $80 \%$ of eyes having improvement in vision and all eyes in the study having a reduction in macular edema. ${ }^{73}$ Since then, several retrospective and prospective studies demonstrating the efficacy of these agents have been published. ${ }^{7,74}$ Maximum improvement in vision appears to occur in the initial few months of treatment with a gradual stabilization thereafter. Schefler et al studied the efficacy of three different ranibizumab regimens in RR: patients either received monthly injections; monthly injection with targeted retinal photocoagulation (TRP); or 3 monthly doses followed by PRN injections and TRP. ${ }^{74}$ After 52 weeks, all subjects entered the treat-and-extend protocol. The authors demonstrated that ranibizumab improves vision and central macular thickness (CMT), and prevents vision loss through 48 weeks. Also, monthly injections were more effective than PRN regimen, and the addition of TRP showed no additional benefits.

Similar results were also obtained from few recent prospective trials on aflibercept. Fallico et al treated radiation-related macular edema with a monthly $2.0 \mathrm{mg}$ intravitreal aflibercept followed by PRN through month 24 and found significant improvement in vision and CMT with an average number of 4.4 injections. $^{75}$ Another study by Murray et al compared a fixed treatment regimen of 6 weeks with a treat and adjust regiment centered around 6 weeks and found that only $5 \%$ of eyes had a BCVA worse than 20/200 with nearly half of eyes maintaining BCVA $20 / 50$ or $^{\text {better. }}{ }^{76}$

\section{Steroids in RM}

Anti-VEGF therapy reduces macular edema by controlling vascular permeability and the formation of new blood vessels via direct inhibition of VEGF. ${ }^{77}$ However, it has also been shown to cause upregulation of intraocular cytokines. ${ }^{78}$ Steroids, with their anti-cytokine properties, are thought to act in such situations. ${ }^{79}$ It also restores the integrity of the inner retinal barrier by increasing tight junction protein and upregulates adenosine, which reduces the osmotic swelling of Muller cells. $^{80,81}$ Initial reports on the use of steroids in RM 
did not yield encouraging results. Horgan et al used $40 \mathrm{mg}$ periocular triamcinolone at plaque application and again 4 and 8 months later and showed a reduced risk of macular edema. ${ }^{82}$ However, the intervention did not benefit the long-term visual outcome with similar rates of moderate and severe vision loss compared to control groups. In another study, Shields et al studied RM secondary to plaque therapy treated with primary IVTA and found that while $91 \%$ of patients' vision stabilized or improved at 1 month. ${ }^{83}$ However, this benefit was reduced to $45 \%$ at 6 months. Thus, none of these studies advocated continuous periodic treatment with steroids. Treatment with intravitreal dexamethasone implant as a primary treatment has also been tried with satisfactory results. ${ }^{84,85}$

\section{Recalcitrant Edema}

Despite improvements in vision in these modalities, discontinuation of treatment with anti-VEGF often results in recurrence of macular edema and a drop in visual acuity. Finger et al conducted a prospective trial that showed stabilization of visual acuity in $70 \%$ eyes treated with $2 \mathrm{mg}$ ranibizumab, with $80 \%$ of eyes having a significant reduction in the central macular thickness of recalcitrant RM by 12 months. ${ }^{73}$ In 2016, Finger et al reported the use of escalating doses of intravitreal anti-VEGF therapy (bevacizumab, ranibizumab) and showed that it can preserve vision (for $80 \%$ of patients for a mean of 38 months). ${ }^{86,87}$ Similar therapeutic benefit was later shown in several other studies, suggesting that RM is a progressive disease requiring increased dosage of the anti-VEGF agent with continuous periodic administration in order to preserve vision. ${ }^{73,88}$ In another study, Kaplan et al showed that the use of intravitreal triamcinolone in edema, not responding to high-dose bevacizumab, can help preserve vision and reduce macular edema. ${ }^{89}$ This response was different from the initial reports on the use of intravitreal steroids in that a higher percentage of patients had stable or improved VA at 6 months. Thus, prior treatment with anti-VEGF agents seems to have a better outcome than using IVTA in treatment-naive eyes. Isolated case reports on the use of aflibercept $^{90}$ and brolucizumab ${ }^{91}$ in recalcitrant edema have also been recently published. Intravitreal dexamethasone implant is another effective treatment option, although Seibel et al demonstrated no difference in VA or central foveal thickness when comparing it with intravitreal bevacizumab and IVTA. ${ }^{92}$ An open-label, randomized, prospective study by Schefler et al, studying the safety of intravitreal $2.0 \mathrm{mg}$ aflibercept is also ongoing and has finished patient enrolment. ${ }^{93}$ Use of pars plana vitrectomy and silicone oil injection at the time of plaque application has also been tried in few studies to reduce radiation damage to the healthy retina, and has been shown to decrease the rates of abnormal macula and lower macular thickness in treated eyes. ${ }^{94}$

The encouraging results from the previous studies favor the role of intravitreal anti-VEGF and steroids for the treatment of radiation maculopathy, and thus can be considered as a first-line treatment. ${ }^{95}$ The results appear to be better if treatment is continued for a longer duration with injection intervals shorter than 90 days. A more intensive treatment regimen, with the help of combination therapy, may be required in more aggressive forms of the disease. Increasing the dose of the antiVEGF agent can be considered as a viable option in cases of recalcitrant macular edema. Caution is advised during the use of intravitreal or periocular steroids due to the risk of glaucoma and cataract formation. However, dexamethasone implants, in general, have a lower risk of these complications and have the added benefit of slow release of the drug that can act for up to 6 months (resulting in a lesser number of injections). ${ }^{95}$ Nonetheless, studies comparing intravitreal anti-VEGF agents with steroids have found no difference in efficacy. ${ }^{96}$ Focal or grid laser, although rarely performed in the current era, can be used in selective cases of recalcitrant macular edema. However, for the treatment of proliferative radiation retinopathy, peripheral laser photocoagulation continues to play a vital role.

\section{Prophylaxis}

Prophylaxis with anti-VEGF agents, steroids or laser, is another extensively studied aspect of RM. ${ }^{95}$ Finger and Kurli reported the use of prophylactic pan-retinal photocoagulation and reported that only (19\%) of the patients developed retinopathy at the end of follow-up. ${ }^{97}$ Reports by Shah et $\mathrm{al}^{98}$ and Shields et al ${ }^{99}$ showed significant benefits in eyes that received intravitreal bevacizumab at the time of plaque removal and every 4 months for 2 years. In both studies, treated eyes had less evidence of radiation maculopathy compared to no treatment at each time point. Kim et al also demonstrated the beneficial effect of 2 monthly injections of ranibizumab on the prevention of retinopathy. ${ }^{7}$ The RadiRet trial demonstrated a similar role in radiation retinopathy, where the authors suggested similar efficacy of PRP and ranibizumab in its prevention. ${ }^{100}$ Thus, treatment with ranibizumab every 2 months and bevacizumab every 4 months after plaque radiotherapy can be administered for the 
prevention of retinopathy and macular edema. Peri-ocular steroids as a prophylactic agent have also been studied. ${ }^{95}$ Patients treated with prophylactic sub-tenon triamcinolone acetonide with or without laser photocoagulation have been shown to have a significantly decreased risk of developing macular edema compared with the control group. ${ }^{101,102}$ However, the authors also demonstrated ocular hypertension rates of around $7-15 \%$ following treatment. ${ }^{82,101}$ Thus, it is recommended not to use peri-ocular steroids as a first-line treatment for prophylaxis in eyes with glaucoma.

\section{Conclusion}

Radiation retinopathy is a potentially blinding condition. Unlike patients undergoing treatment with plaque brachytherapy, who routinely undergo evaluation by retina specialists, those who are treated with EBRT are less likely to be checked by an ophthalmologist. Thus, considering the progressive nature of the disease, it is imperative to follow a regular post-treatment check-up in order to avoid undue delays in diagnosis and treatment.

\section{Meeting Presentation}

The material has not been previously presented at any meeting.

\section{Funding}

There is no funding to report.

\section{Disclosure}

The authors report no conflicts of interest in this work.

\section{References}

1. Finger PT, Chin KJ, Duvall G, Palladium-103 for Choroidal Melanoma Study Group. Palladium-103 ophthalmic plaque radiation therapy for choroidal melanoma: 400 treated patients. Ophthalmology. 2009;116(4):790-6. e1. doi:10.1016/j.ophtha.2008.12.027

2. Finger PT. Radiation therapy for orbital tumors: concepts, current use, and ophthalmic radiation side effects. Surv Ophthalmol. 2009;54 (5):545-568.

3. Finger PT, Pro MJ, Schneider S, Kurli M, Shapira I, Kenneth H. Visual recovery after radiation therapy for bilateral subfoveal acute myelogenous leukemia (AML). Am J Ophthalmol. 2004;138(4):659-662. doi:10.1016/j.ajo.2004.04.047

4. Diener-West M, Earle JD, Fine SL, et al. The COMS randomized trial of iodine 125 brachytherapy for choroidal melanoma, III: initial mortality findings. COMS Report No. 18. Arch Ophthalmol. 2001;119 (7):969-982.

5. Fallico M, Raciti G, Longo A, et al. Current molecular and clinical insights into uveal melanoma. Int J Oncol. 2021;58(4):1. doi:10.3892/ ijo. 2021.5190

6. Stallard HB. Radiant energy as (a) a pathogenic and (b) therapeutic agent in ophthalmic disorders. Gifford Edmonds prize essay for. $\mathrm{Br}$ J Ophthalmol. 1933;6:1-126.
7. Kim IK, Lane AM, Jain P, Awh C, Gragoudas ES. Ranibizumab for the prevention of radiation complications in patients treated with proton beam irradiation for choroidal melanoma (an American Ophthalmological Society thesis). Trans Am Ophthalmol Soc. 2016;2:114.

8. Krema H, Somani S, Sahgal A, et al. Stereotactic radiotherapy for treatment of juxtapapillary choroidal melanoma: 3-year follow-up. $\quad B r \quad J \quad$ Ophthalmol. 2009;93(9):1172-1176. doi:10.1136/bjo.2008.153429

9. Gragoudas ES, Seddon JM, Egan K, et al. Long-term results of proton beam irradiated uveal melanomas. Ophthalmology. 1987;94(4):349-353. doi:10.1016/S0161-6420(87)33456-6

10. Haas A, Pinter O, Papaefthymiou G, et al. Incidence of radiation retinopathy after high-dosage single-fraction gamma knife radiosurgery for choroidal melanoma. Ophthalmology. 2002;109 (5):909-913. doi:10.1016/S0161-6420(02)01011-4

11. Shields CL, Naseripour M, Cater J, et al. Plaque radiotherapy for large posterior uveal melanomas ( $\geq 8$-mm thick) in 354 consecutive patients. Ophthalmology. 2002;109(10):1838-1849. doi:10.1016/S0161-6420(02)01181-8

12. Gündüz K, Shields CL, Shields JA, Cater J, Freire JE, Brady LW. Radiation retinopathy following plaque radiotherapy for posterior uveal melanoma. Arch Ophthalmol. 1999;117(5):609-614. doi:10.1001/archopht.117.5.609

13. Melia BM, Abramson DH, Albert DM, et al. Collaborative ocular melanoma study (COMS) randomized trial of I-125 brachytherapy for medium choroidal melanoma. I. Visual acuity after 3 years COMS report no. 16. Ophthalmology. 2001;108 (2):348-366.

14. Viebahn M, Barricks ME, Osterloh MD. Synergism between diabetic and radiation retinopathy: case report and review. $\mathrm{Br}$ J Ophthalmol. 1991;75(10):629-632. doi:10.1136/bjo.75.10.629

15. Packer S, Rotman M. Radiotherapy of choroidal melanoma with iodine-125. Ophthalmology. 1980;87(6):582-590. doi:10.1016/ S0161-6420(80)35194-4

16. Max Conway R, Poothullil AM, Daftari IK, Weinberg V, Chung JE. Estimates of ocular and visual retention following treatment of extra-large uveal melanomas by proton beam radiotherapy. Arch Ophthalmol. 2006;124(6):838-843. doi:10.1001/archopht.124.6.838

17. Rudoler SB, Corn BW, Shields CL, et al. External beam irradiation for choroid metastases: identification of factors predisposing to long-term sequelae. Int J Radiat Oncol Biol Phys. 1997;38 (2):251-256. doi:10.1016/S0360-3016(97)00050-3

18. Wakelkamp IMMJ, Tan H, Saeed P, et al. Orbital irradiation for Graves' ophthalmopathy: is it safe? A long-term follow-up study. Ophthalmology. 2004;111(8):1557-1562. doi:10.1016/j. ophtha.2003.12.054

19. Stack R, Elder M, Abdelaal A, Hidajat R, Clemett R. New Zealand experience of $\mathrm{I} 125$ brachytherapy for choroidal melanoma. Clin Exp Ophthalmol. 2005;33(5):490-494. doi:10.1111/j.1442-9071.2005.01067.x

20. Takeda A, Shigematsu N, Suzuki S, et al. Late retinal complications of radiation therapy for nasal and paranasal malignancies: relationship between irradiated-dose area and severity. Int J Radiat Oncol Biol Phys. 1999;44(3):599-605. doi:10.1016/ S0360-3016(99)00057-7

21. Wara WM, Irvine AR, Neger RE, Howes EL, Phillips TL. Radiation retinopathy. Int J Radiat Oncol Biol Phys. 1979;5 (1):81-83. doi:10.1016/0360-3016(79)90043-9

22. Kinyoun JL, Lawrence BS, Barlow WE. Proliferative radiation retinopathy. Arch Ophthalmol. 1996;114(9):1097-1100. doi:10.1001/archopht.1996.01100140299007

23. Brown GC, Shields JA, Sanborn G, Augsburger JJ, Savino PJ, Schatz NJ. Radiation retinopathy. Ophthalmology. 1982;89 (12):1494-1501. doi:10.1016/S0161-6420(82)34611-4 
24. Chan RC, Shukovsky LJ. Effects of irradiation on the eye Radiology. 1976;120(3):673-675. doi:10.1148/120.3.673

25. Krema H, Wei X, Payne D, Vasquez LM, Pavlin CJ, Simpson R. Factors predictive of radiation retinopathy post 125 Iodine brachytherapy for uveal melanoma. Can J Ophthalmol. 2011;46 (2):158-163. doi:10.3129/110-111

26. Kumar B, Palimar P. Accelerated radiation retinopathy in diabetes and pregnancy. Eye. 2000;14(1):107-108. doi:10.1038/eye.2000.28

27. Parsons JT, Bova FJ, Fitzgerald CR, Mendenhall WM, Million RR. Radiation retinopathy after external-beam irradiation: analysis of time-dose factors. Int J Radiat Oncol Biol Phys. 1994;30(4):765-773. doi:10.1016/0360-3016(94)90347-6

28. Rodman Irvine A, Alvarado JA, Wara WM, Morris BW, Wood IS. Radiation retinopathy: an experimental model for the ischemicproliferative retinopathies. Trans Am Ophthalmol Soc. 1981;79:103

29. Chacko DC. Considerations in the diagnosis of radiation injury. JAMA. 1981;245(12):1255-1258. doi:10.1001/jama.1981.033103 70045029

30. Dunavoelgyi R, Zehetmayer M, Gleiss A, et al. Hypofractionated stereotactic photon radiotherapy of posteriorly located choroidal melanoma with five fractions at ten Gy-clinical results after six years of experience. Radiother Oncol. 2013;108(2):342-347. doi:10.1016/j.radonc.2013.08.004

31. Monroe AT, Bhandare N, Morris CG, Mendenhall WM. Preventing radiation retinopathy with hyperfractionation. Int J Radiat Oncol Biol Phys. 2005;61(3):856-864. doi:10.1016/ j.ijrobp.2004.07.664

32. Collaborative Ocular Melanoma Study Group. Design and methods of a clinical trial for a rare condition: the Collaborative Ocular Melanoma Study: COMS Report No. 3. Control Clin Trials. 1993;14(5):362-391. doi:10.1016/0197-2456(93)90052-F

33. Shields CL, Shields JA, Cater J, et al. Plaque radiotherapy for uveal melanoma: long-term visual outcome in 1106 consecutive patients. Arch Ophthalmol. 2000;118(9):1219-1228. doi:10.1001/ archopht.118.9.1219

34. Horgan N, Shields CL, Mashayekhi A, Teixeira LF, Materin MA, Shields JA. Early macular morphological changes following plaque radiotherapy for uveal melanoma. Retina. 2008;28 (2):263-273. doi:10.1097/IAE.0b013e31814b1b75

35. Brewington BY, Shao YF, Davidorf FH, Cebulla CM. Brachytherapy for patients with uveal melanoma: historical perspectives and future treatment directions. Clin Ophthalmol. 2018;12:925. doi:10.2147/OPTH.S129645

36. Takiar V, Ranh Voong K, Gombos DS, et al. A choice of radionuclide: comparative outcomes and toxicity of ruthenium-106 and iodine-125 in the definitive treatment of uveal melanoma. Pract Radiat Oncol. 2015;5(3):e169-e76. doi:10.1016/j.prro.2014.09.005

37. Ghassemi F, Sheibani S, Arjmand M, et al. Comparison of iodide-125 and ruthenium-106 brachytherapy in the treatment of choroidal melanomas. Clin Ophthalmol. 2020;14:339. doi: $10.2147 / \mathrm{OPTH} . \mathrm{S} 235265$

38. Filì M, Trocme E, Bergman L, et al. Ruthenium-106 versus iodine-125 plaque brachytherapy of 571 choroidal melanomas with a thickness of $\geq 5.5 \mathrm{~mm}$. Br $J$ Ophthalmol. 2020;104 (1):26-32. doi:10.1136/bjophthalmol-2018-313419

39. Seibel I, Cordini D, Hager A, et al. Predictive risk factors for radiation retinopathy and optic neuropathy after proton beam therapy for uveal melanoma. Graefe's Arch Clin Exp Ophthalmol. 2016;254(9):1787-1792. doi:10.1007/s00417-0163429-4

40. Matet A, Daruich A, Zografos L. Radiation maculopathy after proton beam therapy for uveal melanoma: optical coherence tomography angiography alterations influencing visual acuity. Inv Ophthalmol Vis Sc. 2017;58(10):3851-3861. doi:10.1167/ iovs.17-22324
41. Guyer DR, Mukai S, Egan KM, Seddon JM, Walsh SM, Gragoudas ES. Radiation maculopathy after proton beam irradiation for choroidal melanoma. Ophthalmology. 1992;99 (8):1278-1285. doi:10.1016/S0161-6420(92)31832-9

42. Sorour OA, Mignano JE, Duker JS. Gamma Knife radiosurgery for locally recurrent choroidal melanoma following plaque radiotherapy. Int $J$ Retin Vitr. 2018;4(1):1-5. doi:10.1186/ s40942-018-0123-1

43. Bianciotto C, Shields CL, Pirondini C, Mashayekhi A, Furuta M, Shields JA. Proliferative radiation retinopathy after plaque radiotherapy for uveal melanoma. Ophthalmology. 2010;117 (5):1005-1012. doi:10.1016/j.ophtha.2009.10.015

44. Durkin SR, Roos D, Higgs B, Casson RJ, Selva D. Ophthalmic and adnexal complications of radiotherapy. Act Ophthalmol. 2007;85(3):240-250. doi:10.1111/j.16000420.2006.00822.x

45. Archer DB, Amoaku WMK, Gardiner TA. Radiation retinopathy - clinical, histopathological, ultrastructural and experimental correlations. Eye. 1991;5(2):239-251. doi:10.1038/eye.1991.39

46. Atebara NH, Drouilhet JH, Brown GC. Chapter 36A: Radiation Retinopathy. Duane's ophthalmology on CD-ROM Lippincott Williams \& Wilkins; 2006.

47. Groenewald C, Konstantinidis L, Damato B. Effects of radiotherapy on uveal melanomas and adjacent tissues. Eye. 2013;27 (2):163-171. doi:10.1038/eye.2012.249

48. Archer DB, Gardiner TA. Ionizing radiation and the retina. Curr Opin Ophthalmol. 1994;5(3):59-65. doi:10.1097/00055735199406000-00011

49. Kinyoun JL, Chittum ME, Wells CG. Photocoagulation treatment of radiation retinopathy. Am J Ophthalmol. 1988;105(5):470-478. doi:10.1016/0002-9394(88)90237-1

50. Midena G, Parrozzani R, Frizziero L, Midena E. Chorioretinal Side Effects of Therapeutic Ocular Irradiation: a Multimodal Imaging Approach. J Clin Med. 2020;9(11):3496. doi:10.3390/ jcm9113496

51. Li M, Qiu G, Luo W, Ou J, Li X. Clinical investigation of radiation retinopathy fundus and fluorescein angiographic features. Yan Ke Xuе Bao. 1999;15(3):183-186.

52. Zamber RW, Kinyoun JL. Radiation retinopathy. West $J$ Med. 1992;157(5):530-533.

53. Spaide RF, Borodoker N, Shah V. Atypical choroidal neovascularization in radiation retinopathy. Am J Ophthalmol. 2002;133 (5):709-711. doi:10.1016/S0002-9394(02)01331-4

54. De Salvo G, Hannan SR, James N, Lotery AJ. Retinal angiomatous proliferation occurring after radiotherapy. Eye. 2013;27 (3):447-449. doi:10.1038/eye.2012.274

55. Pang CE, Bailey Freund K. Intravitreal polypoidal choroidal vasculopathy in radiation retinopathy. Ophthalmic Surg Lasers Imaging Retina. 2014;45(6):585-588. doi:10.3928/2325816020141008-04

56. Brown GC, Shields JA, Sanborn G, Augsburger JJ, Savino PJ, Schatz NJ. Radiation optic neuropathy. Ophthalmology. 1982;89 (12):1489-1493. doi:10.1016/S0161-6420(82)34612-6

57. Konstantinidis L, Groenewald C, Coupland SE, Damato B. Transscleral local resection of toxic choroidal melanoma after proton beam radiotherapy. $\mathrm{Br} J$ Ophthalmol. 2014;98(6):775-779. doi:10.1136/bjophthalmol-2013-304501

58. Gupta A, Dhawahir-Scala F, Smith A, Young L, Charles S. Radiation retinopathy: case report and review. $B M C$ Ophthalmol. 2007;7(1):1-5. doi:10.1186/1471-2415-7-6

59. Mukai SGD, Gragoudas ES. Radiation retinopathy. In: Albert DMJF, editor. Principles and Practice of Ophthalmology. Vol. 2. Philadelphia: WB Saunders; 1994:1038-1041.

60. Hayreh SS. Post-radiation retinopathy. A Fluorescence Fundus Angiographic Study. Br J Ophthalmol. 1970;54:705. 
61. Cogan DG. Lesions of the eye from radiant energy. JAMA. 1950;142(3):145-151. doi:10.1001/jama.1950.02910210001001

62. Amoaku WMK, Archer DB. Fluorescein angiographic features, natural course and treatment of radiation retinopathy. Eye. 2021;4 (5):657-667. doi:10.1038/eye.1990.93

63. Finger PT, Kurli M. Laser photocoagulation for radiation retinopathy after ophthalmic plaque radiation therapy. Br J Ophthalmol. 2005;89(6):730-738. doi:10.1136/bjo.2004.052159

64. Shields CL, Say EAT, Samara WA, Khoo CTL, Mashayekhi A, Shields JA. Optical coherence tomography angiography of the macula after plaque radiotherapy of choroidal melanoma. Retina. 2016;36(8):1493-1505. doi:10.1097/IAE.0000000000001021

65. Sellam A, Coscas F, Lumbroso-le Rouic L, et al. Optical coherence tomography angiography of macular features after proton beam radiotherapy for small choroidal melanoma. $\mathrm{Am}$ J Ophthalmol. 2017;181:12-19. doi:10.1016/j.ajo.2017.06.008

66. Skalet AH, Liu L, Binder C, et al. Quantitative OCT angiography evaluation of peripapillary retinal circulation after plaque brachytherapy. Ophthalmol Retina. 2018;2(3):244-250. doi:10.1016/j.oret.2017.06.005

67. Maguire AM. Radiation retinopathy. Retina. 1994;2:1500-1514.

68. Chaudhuri PR, Austin DAVIDJ, Rosenthal ARALPH. Treatment of radiation retinopathy. $\mathrm{Br} J$ Ophthalmol. 1981;65(9):623-625. doi:10.1136/bjo.65.9.623

69. Amoaku WMK, Archer DB. Fluorescein angiographic features, natural course and treatment of radiation retinopathy. Eye. 1990;4 (5):657-667.

70. Hykin PG, Shields CL, Shields JA, Fernando Arevalo J. The efficacy of focal laser therapy in radiation-induced macular edema. Ophthalmology. 1998;105(8):1425-1429. doi:10.1016/ S0161-6420(98)98023-X

71. Mason JO, Albert MA, Persaud TO, Vail RS. Intravitreal bevacizumab treatment for radiation macular edema after plaque radiotherapy for choroidal melanoma. Retina. 2007;27(7):903-907. doi:10.1097/IAE.0b013e31806e6042

72. Gupta A, Muecke JS. Treatment of radiation maculopathy with intravitreal injection of bevacizumab (Avastin). Retina. 2008;28 (7):964-968. doi:10.1097/IAE.0b013e3181706302

73. Finger PT, Chin KJ. High-dose $(2.0 \mathrm{mg})$ intravitreal ranibizumab for recalcitrant radiation retinopathy. Eur J Ophthalmol. 2013;23 (6):850-856. doi:10.5301/ejo.5000333

74. Schefler AC, Fuller D, Anand R, et al. Randomized Trial of Monthly Versus As-Needed Intravitreal Ranibizumab for Radiation Retinopathy-Related Macular Edema: 1-Year Outcomes. Am J Ophthalmol. 2020;216:165-173. doi:10.1016/j.ajo.2020.03.045

75. Fallico M, Reibaldi M, Avitabile T, et al. Intravitreal aflibercept for the treatment of radiation-induced macular edema after ruthenium 106 plaque radiotherapy for choroidal melanoma. Graefe's Arch Clin Exp Ophthalmol. 2019;257(7):1547-1554. doi:10.1007/ s00417-019-04347-6

76. Murray TG, Latiff A, Villegas VM, Gold AS. Aflibercept for radiation maculopathy study: a prospective, randomized clinical study. Ophthalmol Retina. 2019;3(7):561-566. doi:10.1016/j. oret.2019.02.009

77. Finger PT, Chin K. Anti-vascular endothelial growth factor bevacizumab (Avastin) for radiation retinopathy. Arch Ophthalmol. 2007;125(6):751-756. doi:10.1001/archopht.125.6.751

78. Forooghian F, Kertes PJ, Eng KT, Agrón E, Chew EY. Alterations in the intraocular cytokine milieu after intravitreal bevacizumab. Inv Ophthalmol Vis Sc. 2010;51(5):2388-2392. doi:10.1167/ iovs.09-4065

79. Zhang X, Wang N, Schachat AP, Bao S, Gillies MC. Glucocorticoids: structure, signaling and molecular mechanisms in the treatment of diabetic retinopathy and diabetic macular edema. Curr Mol Med. 2014;14(3):376-384. doi:10.2174/ 1566524014666140128114414
80. Gillies MC. Regulators of vascular permeability: potential sites for intervention in the treatment of macular edema. Doc Ophthalmol. 1999;97(3):251-260. doi:10.1023/A:1002196930726

81. Jeon S, Lee WK. Effect of intravitreal triamcinolone in diabetic macular edema unresponsive to intravitreal bevacizumab. Retina. 2014;34(8):1606-1611. doi:10.1097/IAE.0000000 000000109

82. Horgan N, Shields CL, Mashayekhi A, et al. Periocular triamcinolone for prevention of macular edema after iodine 125 plaque radiotherapy of uveal melanoma. Retina. 2008;28(7):987-995. doi:10.1097/IAE.0b013e31816b3192

83. Shields CL, Demirci H, Dai V, et al. Intravitreal triamcinolone acetonide for radiation maculopathy after plaque radiotherapy for choroidal melanoma. Retina. 2005;25(7):868-874. doi:10.1097/ 00006982-200510000-00009

84. Russo A, Avitabile T, Uva M, et al. Radiation macular edema after Ru-106 plaque brachytherapy for choroidal melanoma resolved by an intravitreal dexamethasone $0.7-\mathrm{mg}$ implant. Case Rep Ophthalmol. 2012;3(1):71-76. doi:10.1159/000337144

85. Baillif S, Maschi C, Gastaud P, Caujolle JP. Intravitreal dexamethasone $0.7-\mathrm{mg}$ implant for radiation macular edema after proton beam therapy for choroidal melanoma. Retina. 2013;33 (9):1784-1790. doi:10.1097/IAE.0b013e31829234fa

86. Finger PT, Chin KJ. Intravitreous ranibizumab (Lucentis) for radiation maculopathy. Arch Ophthalmol. 2010;128(2):249-252. doi:10.1001/archophthalmol.2009.376

87. Finger PT, Chin KJ, Semenova EA. Intravitreal anti-VEGF therapy for macular radiation retinopathy: a 10-year study. Eur J Ophthalmol. 2016;26(1):60-66. doi:10.5301/ejo.5000670

88. Meyer CH, Krohne TU, Holz FG. Intraocular pharmacokinetics after a single intravitreal injection of $1.5 \mathrm{mg}$ versus $3.0 \mathrm{mg}$ of bevacizumab in humans. Retina. 2011;31(9):1877-1884. doi:10.1097/IAE.0b013e318217373c

89. Kaplan RI, Chaugule SS, Finger PT. Intravitreal triamcinolone acetate for radiation maculopathy recalcitrant to high-dose intravitreal bevacizumab. Br J Ophthalmol. 2017;101(12):1694-1698. doi:10.1136/bjophthalmol-2017-310315

90. Eleni Loukianou, Georgia Loukianou. Intravitreal aflibercept in recalcitrant radiation maculopathy due to external beam radiotherapy for nasopharyngeal cancer: a first case report. Case Rep Ophthalmol. 2017;8(1):87-90. doi:10.1159/000456535

91. Corradetti G, Corvi F, Juhn A. Short-term outcomes following treatment of recalcitrant cystoid macular edema secondary to radiation maculopathy using intravitreal brolucizumab. $\mathrm{Am}$ $J$ Ophthalmol Case Rep. 2020;20:100981. doi:10.1016/j. ajoc.2020.100981

92. Seibel I, Hager A, Riechardt AI, Davids AM, Böker A, Joussen AM. Antiangiogenic or corticosteroid treatment in patients with radiation maculopathy after proton beam therapy for uveal melanoma. Am $J$ Ophthalmol. 2016;168:31-39. doi:10.1016/j.ajo.2016.04.024

93. US National Library of Medicine. Intravitreal aflibercept injection for radiation retinopathy trial (ARRT); 2018. Available from: https://clinicaltrials.gov/ct2/show/NCT03085784. Accessed June 26, 2021.

94. Tara A, Colin A. Iodine 125 brachytherapy with vitrectomy and silicone oil in the treatment of uveal melanoma: 1-to-1 matched case-control series. Int J Radiat Oncol Biol Phys. 2014;89 (2):347-352. doi:10.1016/j.ijrobp.2014.02.021

95. Fallico M, Chronopoulos A, Schutz JS, Reibaldi M. Treatment of radiation maculopathy and radiation-induced macular edema: a systematic review. Surv Ophthalmol. 2020;1:854.

96. Russo A, Reibaldi M, Avitabile T, et al. Dexamethasone intravitreal implant vs ranibizumab in the treatment of macular edema secondary to brachytherapy for choroidal melanoma. Retina. 2018;38(4):788-794. doi:10.1097/IAE.0000000000001585 
97. Finger PT, Kurli M. Laser photocoagulation for radiation retinopathy after ophthalmic plaque radiation therapy. Br J Ophthalmol. 2005;89:6.

98. Shah SU, Shields CL, Bianciotto CG, et al. Intravitreal bevacizumab at 4-month intervals for prevention of macular edema after plaque radiotherapy of uveal melanoma. Ophthalmology. 2014;121(1):269-275. doi:10.1016/j.ophtha.2013.08.039

99. Shields CL, Dalvin LA, Chang M, et al. Visual outcome at 4 years following plaque radiotherapy and prophylactic intravitreal bevacizumab (every 4 months for 2 years) for uveal melanoma: comparison with nonrandomized historical control individuals. JAMA Ophthalmol. 2020;138(2):136-146. doi:10.1001/ jamaophthalmol.2019.5132
100. Seibel I, Vollhardt D, Riechardt AI, et al. Influence of Ranibizumab versus laser photocoagulation on radiation retinopathy (RadiRet)-a prospective randomized controlled trial. Graefe's Arch Clin Exp Ophthalmol. 2020;258(4):869-878. doi:10.1007/s00417-020-04618-7

101. Horgan N, Shields CL, Mashayekhi A, et al. Periocular triamcinolone for prevention of macular edema after plaque radiotherapy of uveal melanoma: a randomized controlled trial. Ophthalmology. 2009;116(7):1383-1390. doi:10.1016/j.ophtha.2009.01.051

102. Materin MA, Bianciotto CG, Chengqing W, Shields CL. Sector laser photocoagulation for the prevention of macular edema after plaque radiotherapy for uveal melanoma: a pilot study. Retina. 2012;32(8):1601-1607. doi:10.1097/IAE.0b013e3182437e70

\section{Publish your work in this journal}

Clinical Ophthalmology is an international, peer-reviewed journal covering all subspecialties within ophthalmology. Key topics include: Optometry; Visual science; Pharmacology and drug therapy in eye diseases; Basic Sciences; Primary and Secondary eye care; Patient Safety and Quality of Care Improvements. This journal is indexed on PubMed

Submit your manuscript here: https://www.dovepress.com/clinical-ophthalmology-journal
Central and CAS, and is the official journal of The Society of Clinical Ophthalmology (SCO). The manuscript management system is completely online and includes a very quick and fair peer-review system, which is all easy to use. Visit http://www.dovepress.com/ testimonials.php to read real quotes from published authors. 